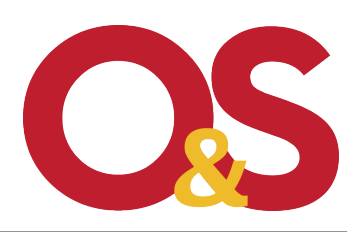

Revista Organizações \& Sociedade

2020, 27(92), $15-34$

\title{
Concepções de trabalho e desenvolvimento da competência profissional: estudo fenomenográfico com agentes locais de inovação do SEBRAE
}

(1) Autor(es) 2020

DOI 10.1590/1984-9270921

ISSN 1984-9230

www.revistaoes.ufba.br

Concepts of Work and Professional Competence Development: a

Phenomenographic Study with SEBRAE's Local Innovation Agents

NPGA, Escola de Administração

Universidade Federal da Bahia

Recebido: 01/09/2017

Aprovado: 29/03/2019

Rubens de Araújo Amaroa

anniversidade Federal do Espírito Santo, Vitória, ES, Brasil

\section{Resumo}

Embora possua grande potencial para os estudos da competência, a fenomenografia ainda é pouco utilizada no país. Os estudos fenomenográficos têm documentado que as concepções de trabalho dos indivíduos dirigem sua aprendizagem para desempenhá-lo bem, pois são essas concepções que criam, formam e organizam os atributos (conhecimentos, habilidades e outros) postos em jogo para realizá-lo. Para desenvolver competências profissionais, as pesquisas sugerem que os indivíduos devem passar de concepções de trabalho superficiais para outras mais profundas. Contudo, há carência de estudos que identifiquem, empiricamente, gatilhos dessa mudança. Esse artigo visa a preencher essa lacuna. Seu objetivo foi analisar o processo de mudança de concepções de trabalho de um grupo de Agentes Locais de Inovação. Os dados foram coletados por meio de entrevistas e analisados a partir de protocolos fenomenográficos. Foram identificados a "pressão das metas" e o "desejo de realizar um trabalho de qualidade" como gatilhos da mudança de concepções e do desenvolvimento de novas competências.

Palavras-chave: Concepções de Trabalho; Desenvolvimento de Competências; Reflexividade; Fenomenografia; Agentes Locais de Inovação.

\begin{abstract}
Phenomenography is still little used in Brazil despite its great potential for competence studies. Research in this field has show that the individuals' conceptions of work direct their learning so that they perform it well, since it is these conceptions forge, constitute, and organize attributes (knowledge, skills, and others) used to accomplish it. In order to develop professional competence, researchers suggest that individuals should move from less superficial work conceptions to more comprehensive ones. However, there is a lack of studies that empirically identify the triggers of this change. This article is intended to fill such gap. Its objective was to analyze the process of change in working conceptions of a group of Local Innovation Agents. Data were collected through interviews and analyzed by means of phenomenographic protocols. The "pursuit of goals" and the "desire to carry out quality work" were identified as triggers of changes in conceptions' changes and the development of new competencies.
\end{abstract}

Keywords: Conceptions of Work; Competence Development; Reflexivity; Phenomenography; Local Innovation Agents. 


\section{Introdução}

Boa parte dos estudos no campo da competência profissional costuma oscilar entre perspectivas que focalizam diferentes unidades de análise. Há aqueles que, tendo sua origem nos estudos da psicologia estadunidense (McClelland, 1973), focalizam o indivíduo e, como decorrência, conceituam a competência como um conjunto de atributos individuais que se relacionam com o alto desempenho. Por outro lado, há estudos que definem a competência a partir da análise do conjunto de atividades ligadas às ocupações (LeDeist \& Winterton, 2005). Assim, a competência é definida como um conjunto de atributos requerido pelas funções desempenhadas pelos indivíduos. Há, ainda, estudos que, seguindo a tradição francesa (Zarifian, 2001; LeBoterf, 2003) definem a competência como uma mobilização de recursos internos e externos ao indivíduo para enfrentar situações específicas em suas atividades laborais. No Brasil, muitos estudos se inspiram nessas diferentes tradições, definindo a competência como um conjunto de saberes em ação, que geram valor social para os indivíduos e valor econômico para as organizações (Fleury \& Fleury, 2001), ou como um cluster de atributos individuais que afetam o desempenho do papel profissional a partir daquilo que os indivíduos entregam à organização (Dutra, 2008).

Apesar das divergências nas escolhas das unidades de análise, o campo de estudo da competência tem sido dominado pela abordagem racionalista, que sustenta uma visão dualista e objetiva da realidade. Indivíduos e atividades são tomados como duas unidades de análise distintas, descritíveis e mensuráveis. Em decorrência dessa dicotomia, a competência dos profissionais é descrita ora como um conjunto de atributos individuais, ora como requisitos para o exercício de determinada atividade (Sandberg, 2000; Sandberg \& Targama, 2007).

Visando a superação dessa dicotomia, Sandberg (2000) apresentou a fenomenografia como método para descrever a competência humana nas organizações. Desenvolvida em meados dos anos 1970, na área de Educação, por um grupo de pesquisadores da Universidade de Gotemburgo (Marton \& Säljö, 1976), na Suécia, a fenomenografia é uma modalidade de pesquisa qualitativa, cujo objetivo é mapear e descrever as diferentes formas que um fenômeno pode ser experienciado por indivíduos ou grupos (Marton, 1981). Essas diferentes maneiras de experienciar os fenômenos são chamadas de concepções.

Sandberg (2000) utilizou a fenomenografia para estudar a competência profissional de um grupo de engenheiros da Volvo, responsáveis pela otimização de motores. Foram identificadas três concepções diferentes que os engenheiros tinham sobre seu trabalho. Os resultados da pesquisa mostraram que a concepção particular que um trabalhador tem do seu trabalho define quais atributos (conhecimentos, habilidades e outros) ele aciona e utiliza para desempenhá-lo bem.

Outros estudos fenomenográficos no campo da competência em organizações têm sido realizados fora do país (Partington, Pellegrinelli \& Young, 2005; Chen, Partington \& Wang, 2008) e no Brasil (Amaro \& Brunstein, 2013; 2014; Brunstein, Heidrich \& Amaro, 2016; Jardim \& Rocha-Pinto, 2017). Contudo, pesquisas fenomenográficas nesse campo ainda são escassas no país, mesmo que essa abordagem tenha sido apresentada por Barbosa e Rodrigues (2006) e Bitencourt, Azevedo e Froehlich (2013) como uma alternativa metodológica para estudar as competências. Mesmo na área da Administração há poucos estudos utilizando a fenomenografia. Em uma revisão sistemática, sem delimitação temporal, realizada por Santos, Alperstedt, Leal, e Feuerschutte (2018), no portal de teses e dissertações da Capes e na base de artigos Spell, foram encontrados apenas 4 teses, 11 dissertações e 11 artigos. Esse número de estudos é ainda menor, considerando o fato de que os artigos foram originados das dissertações e teses. Para Cherman e Rocha-Pinto (2016) essa escassez de estudos utilizando a fenomenografia decorre do pouco conhecimento dos pesquisadores a respeito da existência do método e suas possibilidades.

Apesar da baixa utilização da fenomenografia nos estudos organizacionais e, especificamente, no campo da competência, esse método tem sido largamente utilizado em outras áreas. Em geral, nesses estudos 
busca-se mapear as diferentes concepções de indivíduos e grupos do fenômeno estudado. Mann, Dall'Alba e Radcliffe (2007) destacaram a importância de identificar as diferentes formas que um fenômeno é concebido por determinados grupos. Para esses autores, o desenvolvimento profissional é marcado pela mudança de concepções mais simples para aquelas mais profundas de trabalho. Portanto, mudar uma concepção pode ser tão ou mais importante do que aprender um conjunto de habilidades.

Na mesma direção, Sandberg e Dall'Alba (2006) propuseram diálogos reflexivos como uma maneira de desenvolver a competência no trabalho a partir da mudança de concepções dos indivíduos. Ainda que alguns pesquisadores tenham proposto diferentes formas de promover mudanças nas concepções de trabalho das pessoas, há carência de estudos que identifiquem, empiricamente, os gatilhos que levam à essas mudanças. Esse artigo preenche essa lacuna a partir de uma pesquisa fenomenográfica realizada com um grupo de participantes do programa ALI - Agentes Locais de Inovação do Sebrae/ES.

O objetivo desse estudo foi analisar o processo de mudança de concepções de trabalho de um grupo de ALI - Agentes Locais de Inovação do Sebrae/ES e sua influência no desenvolvimento de competências desses agentes.

Este artigo divide-se em cinco seções além desta introdução. A segunda seção apresenta a fenomenografia e seu potencial para o desenvolvimento da competência profissional. A terceira seção apresenta o percurso metodológico e o campo da pesquisa. Na quarta, são apresentados e discutidos os achados da pesquisa e, na última seção, são apresentadas algumas reflexões e implicações do uso da fenomenografia para o desenvolvimento da competência de profissionais.

\section{Fenomenografia e desenvolvimento da competência profissional}

A fenomenografia foi desenvolvida por estudiosos da Universidade de Gotemburgo, que tentaram responder à questão: por que algumas pessoas aprendem melhor do que outras? (Marton \& Säljö, 1976). Um grupo de estudantes foi convidado a ler um texto e, após a leitura, participar de uma entrevista individual com os pesquisadores para discutir seu entendimento do texto. A entrevista abrangeu também questões a respeito de sua experiência da leitura. Foram identificadas maneiras completamente diferentes de entender o texto (Marton, 1994).

Os pesquisadores poderiam abordar essas diferenças a partir de perspectivas diversas. Se adotassem uma perspectiva de primeira ordem, elaborariam um conjunto de sentenças a respeito das propriedades gerais da mente humana, de um lado, e/ou do contexto onde a aprendizagem se deu, de outro. Assim, assumiriam a existência de uma realidade que está do lado de fora dos sujeitos esperando para ser descoberta, ou seja, o texto teria um significado único que os alunos precisariam descobrir. Sujeito (alunos) e realidade (texto) seriam tomados como duas entidades distintas que poderiam ser estudadas separadamente (Marton, 1981).

Contudo, os pesquisadores adotaram uma perspectiva de segunda ordem, pois buscaram compreender as diferenças de interpretação a partir da ação dos estudantes para compreender o texto, da sua experiência de leitura. Ao tomar a experiência de leitura do texto como ponto de partida, em vez do texto como tal, as diferentes compreensões apareceram não como um problema de entendimento de seu significado, mas como resultado de como os estudantes o experienciaram (Marton, 2000).

As diferentes maneiras de experienciar o texto foram chamadas de concepções (expostas na forma de categorias de descrição), que foram hierarquizadas (da mais superficial à mais profunda) dentro daquilo que os pesquisadores chamaram de espaço de resultados. Assim, esse espaço não apenas mostrou o número limitado de compreensões do fenômeno (texto), mas forneceu um instrumento para caracterização, em termos qualitativos, de como os alunos concluíram com menor ou maior êxito sua tarefa de aprender (Marton, 1994). 
Para os fenomenógrafos, aprender é uma mudança na capacidade de uma pessoa de experienciar algo no mundo. Isso equivale a tornar-se capaz de discernir certos aspectos de um fenômeno e ser capaz de mantê-los na consciência focal, simultaneamente. Discernimento e simultaneidade são, portanto, características-chave da aprendizagem de acordo com este ponto de vista (Fazey \& Marton, 2002). Discernir significa que uma característica do mundo físico, cultural ou simbólico aparece para o sujeito, e é visto ou sentido por ele no contexto de suas experiências anteriores de algo mais ou menos diferente. Nesse sentido, a experiência do mundo não é apenas cognitiva, mas também sensível (Strati, 2007). Destarte, não é possível discernir ou experienciar algo "como tal". O discernimento ou experiência é sempre o discernimento da variação ou a experiência da diferença. A escuridão apenas pode ser experienciada como um contraste da luz vivenciada (ou imaginada). Não se pode experienciar uma cor qualquer sem experienciar as outras cores. Sem a variação das cores, a ideia de cor sequer existiria (Marton \& Trigwell, 2000).

0 primeiro a perceber o potencial da fenomenografia para os estudos da competência profissional foi Sandberg (2000). Em sua revisão dos estudos sobre o tema, percebeu que a maioria das pesquisas abordava 0 fenômeno da competência separando sujeito e objeto. Enquanto alguns estudos compreendiam a competência a partir da identificação de um conjunto de atributos dos indivíduos (abordagens orientadas para o trabalhador), outros buscavam identificar a competência a partir análise das atividades desempenhadas por esses indivíduos (abordagens orientadas para o trabalho).

A pesquisa fenomenográfica de Sandberg (2000) com um grupo de engenheiros da Volvo responsáveis pela otimização de motores buscou compreender, a partir do ponto de vista deles, a competência envolvida nesta atividade. $\mathrm{O}$ objetivo era compreender o que consistia a competência humana no trabalho. Para esse autor, sem tal compreensão, o desenvolvimento da competência não pode ser gerenciado de maneira eficaz. Os resultados da pesquisa apontaram para três formas diferentes de conceber (experienciar) o trabalho de otimização.

Esse estudo mostrou que a competência humana não é, essencialmente, um conjunto específico de atributos. Em vez disso, o conhecimento, as habilidades e outros atributos utilizados pelas pessoas para realizar o trabalho são precedidos por, e baseados em suas concepções do trabalho. São as concepções que criam, formam e organizam os atributos postos em jogo para realizá-lo. Em outras palavras, a concepção específica que o trabalhador tem do trabalho define qual competência ele desenvolve e utiliza para desempenhá-lo (Sandberg, 2000).

Esta forma de descrever a competência pode ser vista como uma possibilidade de superação das limitações dos modelos racionalistas observadas por McKenna (1999). Esse autor mostrou que as descrições dos atributos da competência, que constituem esses modelos, tendem a ser abstratas e distantes da realidade de trabalho das pessoas, porque um atributo assume o mesmo significado independente do contexto em que ocorre. Contudo, sob a abordagem fenomenográfica, as maneiras como os trabalhadores concebem seu trabaIho criam e dão forma ao contexto em que os atributos adquirem significados específicos para o desempenho competente do trabalho (Sandberg \& Targama, 2007).

Sandberg (2000), Sandberg e Dall'Alba (2006) e Sandberg e Targama (2007) afirmam que a variação no desempenho não está relacionada, em primeiro plano, a um conjunto específico de atributos detidos por aqueles indivíduos considerados mais competentes. Em vez disso, a razão pela qual algumas pessoas desempenham determinado trabalho melhor do que outras está relacionada às concepções de trabalho que possuem.

Tais evidências fornecem uma compreensão alternativa sobre como a competência profissional pode ser desenvolvida. Enquanto as abordagens orientadas para o trabalho e para o trabalhador consideram 0 desenvolvimento da competência uma aquisição de atributos, à luz da fenomenografia, a mudança nas concepções de trabalho torna-se a forma mais fundamental de desenvolvimento. Baseado nisso, Sandberg (2000) propõe duas formas de desenvolvimento de competência profissional: (i) mudar a concepção atual para outra concepção de trabalho; (ii) desenvolver e aprofundar as maneiras atuais de conceber o trabalho. 
Essas duas formas de desenvolvimento podem ser mais bem compreendidas a partir dos estudos de Mann, Dall'Alba e Radcliffe (2007). Para esses autores, o desenvolvimento profissional costuma ser entendido como um processo gradual de passagem por estágios pré-fixados - do aprendiz ao expert. Nesse modelo, tornar-se um profissional mais competente significa dominar conteúdos cognitivos e repertórios de ação requeridos em cada etapa. A compreensão, nesse modelo, restringe-se ao domínio de determinados conteúdos.

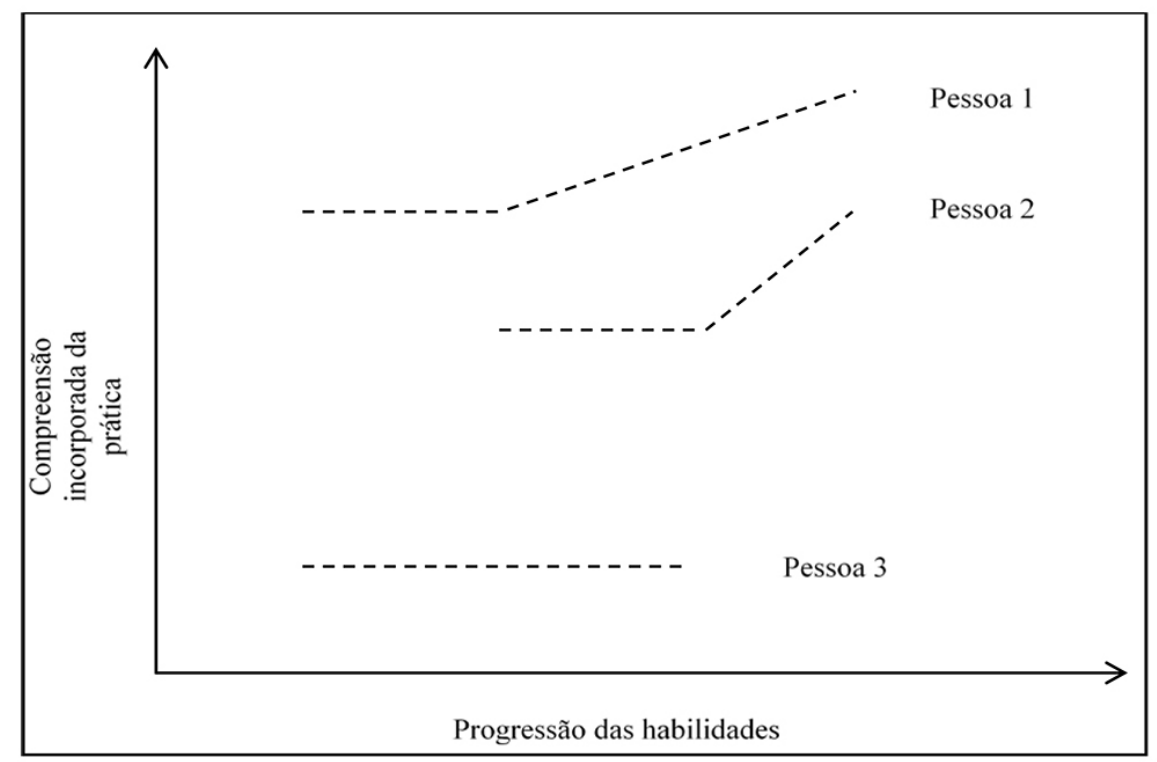

Figura 1 - Modelo de Desenvolvimento Profissional Fonte: Adaptado de Mann, Dall'Alba e Radcliffe (2007).

Contudo, sob a perspectiva fenomenográfica, a compreensão (ou concepção) está imbricada em uma prática intersubjetiva que integra o saber, o agir e o ser. Essa compreensão incorporada costuma ser denominada como um desdobramento de um modo de ser profissional (Dall'Alba, 2004; Dall'Alba \& Sandberg, 2006; Dall'Alba, 2009; Sandberg \& Pinnington, 2009). Nesse sentido, os profissionais não aprendem apenas conhecimentos e habilidades, mas são renovados ao longo do tempo enquanto vão se integrando às formas de ser o profissional em questão. Por isso, as diferentes concepções de uma prática profissional são fundamentais para a maneira como o indivíduo a desempenha e desenvolve.

Essa ideia forma a base do modelo de desenvolvimento profissional sob a perspectiva fenomenográfica, conforme proposto por Mann, Dall'Alba e Radcliffe (2007), mostrado na Figura 1.

Esse modelo apresenta algumas possíveis trajetórias de desenvolvimento. 0 eixo horizontal mostra a progressão das habilidades (atributos da competência). 0 eixo vertical representa as maneiras qualitativamente diferentes em que uma prática particular é compreendida e executada. O modelo mostra que o desenvolvimento de novas habilidades não significa, necessariamente, uma mudança na concepção de trabalho. É possível aprender e tornar-se mais do mesmo. Em contrapartida, a mudança de concepção leva ao desenvolvimento de novos atributos da competência profissional em questão.

Embora Sandberg (2000) e Sandberg e Dall'Alba (2006) tenham proposto um conjunto de intervenções para desenvolver competência no trabalho a partir da mudança de concepções, não foram identificadas pesquisas empíricas que documentassem essas mudanças na literatura fora da área de Educação. Na área da competência, os estudos têm se restringido ao mapeamento das concepções. Por exemplo, Kettunen, Sampson, Vuorinen (2015) identificaram quatro concepções de uso das mídias sociais para orientação de carreiras 
entre profissionais dinamarqueses e finlandeses. Essas concepções constituíram diferentes competências na prática de orientar carreiras. Brunstein, Heidrich e Amaro (2016) mapearam as variações das concepções dos gestores sobre o significado de Fair Play nas organizações, e identificaram diferentes competências associadas a cada uma delas. Jardim e Rocha-Pinto (2017) mapearam três concepções distintas de competência nas rotinas de programação da produção de um grupo de programadores.

Em outros estudos na área de Administração, o foco também tem sido mapear as diferentes concepções dos fenômenos. O'Leary e Sandberg (2017) investigaram como gestores de firmas de serviços profissionais gerenciam a diversidade e identificaram quatro concepções para administrar e conduzir a diversidade. Goff (2017) realizou uma pesquisa fenomenográfica com administradores universitários da Província de Ontário, no Canadá, e identificou três concepções diferentes de garantia da qualidade. Lamb, Sandberg e Liesch (2018) utilizaram a fenomenografia para investigar como proprietários-gerentes de pequenas vinícolas australianas praticam a internacionalização e identificaram quatro formas distintas.

O presente artigo não apenas mapeia as concepções de trabalho de um grupo de agentes locais de inovação, como identifica os gatilhos que levaram à mudança de uma concepção menos para uma mais profunda.

\section{Percurso metodológico e o campo de pesquisa}

Essa pesquisa é caracterizada como fenomenográfica, que é uma abordagem qualitativa cujo objetivo central é mapear as diferentes formas que os fenômenos podem ser experienciados, conceituados, compreendidos, percebidos e apreendidos pelos indivíduos (Marton, 2000). A fenomenografia adota como pressuposto uma ontologia relacional, ou seja, sujeito e objeto não são tomados como duas entidades distintas. 0 objeto de estudo da fenomenografia não é o fenômeno em si, nem as estruturas cognitivas dos indivíduos. 0 foco da atenção é a relação entre os sujeitos e tal fenômeno (Bowden, 2005).

Ao tomar como objeto de estudo a relação entre os sujeitos e o fenômeno, a fenomenografia focaliza a experiência desses sujeitos. Ao manter esse foco, assume que "[...] a experiência é relacional, não é puramente objetiva, independente da pessoa, nem puramente subjetiva, independente do mundo" (Mann, Dall'Alba \& Radcliffe, 2007, p. 6). Essa postura não-dualista da fenomenografia decorre da incorporação de aspectos do pragmatismo filosófico (Feldon \& Tofel-Grehl, 2018).

O campo de pesquisa foi o programa Agentes Locais de Inovação (ALI), que já tem sido objeto de pesquisas no país. Neto e Teixeira (2014) estudaram esse programa e buscaram mensurar o grau de inovação de 1.260 micro e pequenas empresas no Sergipe a partir de uma survey. Colbari (2014) realizou uma pesquisa qualitativa para analisar a cultura de inovação presente nas micro e pequenas empresas do Espírito Santo, atendidas pelo programa. Porém, os estudos realizados têm os processos de inovação como unidade analítica. A aprendizagem e o desenvolvimento de competências dos agentes ainda não foram estudados.

Os sujeitos de pesquisa foram os 13 agentes locais de inovação, doravante denominados ALI, participantes do programa no ciclo 2014-2016. 0 grupo é composto por 11 participantes do sexo feminino e 2 do sexo masculino. A idade dos ALI varia entre 25 e 32 anos (média de 28 anos) e a sua formação é bastante variada: Administração (5), Arquitetura e Urbanismo (2), Ciências Contábeis (1), Ciências Econômicas (1), Ciências Sociais (1), Comunicação Social (1), Design de Moda (1) e Tecnólogo em Gestão de Produção e Distribuição de Petróleo (1). Além dos ALI, foi entrevistada a Coordenadora do Programa.

Embora haja diferentes formas de coleta de dados em pesquisas fenomenográficas, tais como experimento (Marton \& Säljö, 1976), observação (Dall'Alba, 2004) e solução de problemas (Bowden, 2000), o método de coleta de dados predominante em uma pesquisa fenomenográfica é a entrevista individual em profundidade (Bowden, 2005). As entrevistas foram realizadas nos meses em que os ALI estavam concluindo sua participação no programa. 
Como o objeto de análise da pesquisa fenomenográfica é a experiência dos sujeitos e não as teorias esposadas sobre os temas tratados, o roteiro de entrevista foi inspirado nos protocolos sugeridos por Dall'Alba (2004) e Åkerlind (2005). Assim, manteve-se o foco sobre o que foi vivenciado bem como sobre as maneiras que os sujeitos construíram sentido de suas experiências. Vale ressaltar que, na fenomenografia, a entrevista tem o papel de facilitar a tematização dos aspectos da experiência do sujeito não previamente tematizados. As experiências do fenômeno (concepções) não estão prontas previamente antes da entrevista para serem lidas, nem são apenas construções sociais situacionais. São aspectos da experiência do sujeito que mudam de comumente irrefletidos para serem refletidos (Marton, 1994).

O objetivo principal do processo de análise de dados em uma pesquisa fenomenográfica é a construção de categorias de descrição, ou seja, a descrição das concepções que os sujeitos de pesquisa possuem do fenômeno (Bowden, 2005). Esse processo é realizado a partir da transcrição das entrevistas, que, nessa pesquisa, resultaram em pouco mais de 18 horas de gravação e geraram 290 páginas de transcrição.

A análise seguiu o protocolo sugerido por Sjöström e Dahlgren (2002): (1) Familiarização: várias leituras das transcrições para começar a se apropriar de seu conteúdo. (2) Compilação: agrupamento das respostas dos entrevistados a cada questão realizada na entrevista. (3) Condensação: redução das respostas dos entrevistados para encontrar os elementos centrais. (4) Agrupamento preliminar: classificação das respostas similares em grupos provisórios. Essa análise apresenta uma lista inicial das categorias de descrição. (5) Comparação preliminar: Estabelecimento das fronteiras entre as categorias. Nesse momento, os grupos preliminares devem ser revisados com rigor. Isso implica na comparação de cada categoria com as outras, com o objetivo de verificar se não há grupos semelhantes e se esses, de fato, contemplam as diferentes maneiras de conceber o fenômeno estudado. (6) Nomear as categorias: ênfase na sua essência, tomando como base os atributos internos de cada grupo. É muito importante que os nomes representem não apenas os conteúdos descritos em cada grupo, mas também sejam capazes de expressar as diferenças entre eles. (7) Elaboração do espaço de resultados do fenômeno: apresentação das diferentes concepções do fenômeno estudado. Além de apresentar as diferentes concepções, o espaço de resultados mostra a relação existente entre elas.

Em geral, a validação dos dados nas pesquisas fenomenográficas utiliza a técnica "advogado do diabo", onde outros pesquisadores testam as categorias identificadas contra as transcrições (Bowden, 2005). Porém, como esta pesquisa foi realizada por um pesquisador, foi seguida a sugestão de Åkerlind (2005), que recomenda que ele exerça esse papel. Para isso, foi necessário que cada concepção, com sua categoria de descrição, fosse testada contra as transcrições.

\section{Resultados}

O programa Agentes Locais de Inovação apresenta como foco a promoção e disseminação da cultura de inovação nos pequenos negócios por meio de bolsistas contratados por um Acordo de Cooperação entre o Serviço Brasileiro de Apoio às Micro e Pequenas Empresas - Sebrae e o Conselho Nacional de Desenvolvimento Científico e Tecnológico - CNPq. Esses bolsistas, durante 2 meses, foram capacitados pelo Sebrae para acompanharem, pelo período de 24 meses, um conjunto de 50 empresas de determinados segmentos empresariais e/ou região.

O modelo de atuação do programa ALI foi inspirado nas experiências dos agentes de inovação da Índia, dos agentes de saúde no Brasil e dos técnicos extensionistas da Empresa Brasileira de Pesquisa Agropecuária - Embrapa. O programa oferece apoio e assistência aos empresários de pequenos negócios de forma gratuita (os empresários cobrem apenas custos de ações que requeiram aquisição de serviços e/ou produtos), continuada (acompanhamento durante toda a duração do programa), especializada (os agentes são orientados por consultores seniores do Sebrae) e ativa (os agentes se deslocam até os empresários).

Os agentes locais de inovação seguem um fluxo de atuação que se desdobra nas seguintes etapas: 
- Etapa 1: os agentes devem prospectar empresas, sensibilizar os empresários para que estes participem do programa e fazer a adesão de 50 empresas, solicitando aos empresários a assinatura de um termo;

- Etapa 2: dá início ao Ciclo 0, como é conhecida a primeira rodada de assistência. Neste ciclo, os agentes devem na primeira visita ao empresário, aplicar o diagnóstico empresarial (mesmo do Prêmio MPE Brasil); lançar os resultados no sistema utilizado pelo programa; na segunda visita, aplicar o Radar da Inovação R0; lançar dados do Radar no sistema; com base no diagnóstico e Radar, elaborar uma matriz SWOT para a empresa; preparar o documento de devolutiva; validar a matriz SWOT e o Radar com o consultor sênior; realizar a devolutiva com o empresário, elaborando em conjunto, um Plano de Ação PO (neste momento, o agente deve ter conhecimento dos produtos e serviços oferecidos pelo Sebrae e demais parceiros, para indicar aos empresários); o plano de ação é validado pelo consultor sênior e lançado no sistema; o plano validado é apresentado ao empresário em uma reunião devolutiva final, na quarta visita.

- Etapa 3: o ALI monitora e acompanha a execução do plano de ação pelo empresário. Caso tenham sido realizadas três das cinco ações de gestão e de inovação planejadas, o plano de ação é finalizado, podendo o ALI iniciar um novo ciclo. Em média, cada ciclo teve a duração de 6 meses.

Depois da Etapa 3, começa um novo ciclo com novos diagnósticos e planos de ação até o encerramento, com o fim de verificar a efetividade das ações realizadas na empresa, a partir da análise dos Radares (R0, R1 e R2) e da consolidação dos indicadores propostos nos Planos de Ação (PA0, PA1 e PA2).

Antes de discorrer sobre as concepções de trabalho dos agentes locais de inovação, é importante entender o conceito de inovação adotado pelo grupo. O programa utiliza o Manual de Oslo (OCDE, 2005) como referência, assumindo a inovação como a implementação: de um produto (bem ou serviço) novo ou significativamente melhorado; de um processo (método de produção ou de distribuição) novo ou significativamente melhorado; de um método de marketing novo; de um método organizacional novo.

Contudo, dadas as condições dos pequenos negócios - falta de estrutura e de organização - identificados nas visitas dos $A L I$, o conceito de inovação vai sendo modificado. Assim, inovação passa a ser introdução de qualquer procedimento que seja novo para a empresa e que gere algum retorno. A ALI-3 afirma que se "[...] a empresa não tem um certo tipo de procedimento, queira ou não, se ela implementar isso, vai ser uma inovação". Outras ALI vão na mesma direção: "No contexto de micro e pequena empresa a maior parte são inovações incrementais. Às vezes, a pessoa não tem nenhuma ferramenta de gestão, desenvolveu visão, missão, criou site, Facebook, identidade visual, logo, placa etc., isso é inovação." (ALI-10)

Então, quando tem um plano de ação e a gente joga no sistema, tem como você marcar: inovação ou gestão, então a gente entendeu que novo para a empresa, mesmo sendo algo super comum, mas que ela nunca fez e isso vai causar um impacto, então a gente marca como uma ação de inovação. (ALI-6)

Cabe agora descrever as duas concepções de trabalho encontradas entre os agentes locais de inovação. Essas concepções são apresentadas a seguir:

- Concepção 1 - ALI como consultor de vendas: o trabalho consiste em prospectar empresas de forma quantitativa para o programa, diagnosticar suas necessidades utilizando as ferramentas Radar e Diagnóstico, e recomendar ações indicando, preferencialmente, as soluções disponíveis no Sebrae. $O$ atingimento das metas (adesão de empresas, número de visitas, planos de ação etc.) é a medida de sucesso do trabalho. 
- Concepção 2 - ALI como consultor de empresas: o trabalho consiste em prospectar empresas de forma qualitativa para o programa, diagnosticar suas necessidades a partir da observação e de conversas com empresários, e recomendar ações aprendidas informalmente. A qualidade das ações é a medida de sucesso do trabalho.

\title{
ALl como consultor de vendas
}

0 período de capacitação de dois meses é planejado nas modalidades presencial e à distância. No programa de capacitação, que mescla metodologias expositivas e vivenciais, os ALI recebem treinamentos, entre outros conteúdos, sobre: o programa de inovação do Sebrae para as pequenas empresas; inovação e gestão da inovação; gestão da pequena empresa; prospecção e negociação; administração do tempo; Radar de Inovação e Diagnóstico Empresarial (MPE Brasil), que são as principais ferramentas do programa. Além da capacitação, os ALI são estimulados a refletir sobre seu processo de aprendizagem a partir da criação de um blog, que é monitorado por um tutor. Esse modelo de formação se baseia na ideia compartilhada por muitos autores de que a reflexão, como reconstrução da experiência, potencializa a aprendizagem (Kolb, 1984).

Durante o período de capacitação, os ALI começaram a construir e consolidar, intersubjetivamente, uma concepção de trabalho. Essa concepção tem relação com o que é idealizado pelo Sebrae em relação às atividades que devem ser desempenhadas pelos ALI. Nas palavras da coordenadora do programa:

\begin{abstract}
Eles têm que captar 50 empresas e fazer o diagnóstico. Em cima desse diagnóstico eles verificam qual a necessidade da empresa e criam um plano de ação junto ao cliente. Eles não podem inventar uma consultoria para o cliente e falarem "toma aqui". Não, o cliente tem que aceitar aquilo ali. Então, eles entregam esse plano de ação e monitoram, todo mês eles vão ou ligam, verificam se a empresa está precisando de orientação, se está precisando que abra essa demanda. Faz esse apoio, esse monitoramento. O ALI não executa nenhum tipo de consultoria, ele faz um monitoramento, faz o diagnóstico, aplica o plano de ação e faz o monitoramento. (Coordenadora do Programa)
\end{abstract}

Os ALI passam a compartilhar a concepção de que seu trabalho está relacionado à capacidade de utilizar as ferramentas do programa para realizar diagnósticos e, então, identificar as soluções institucionais que atendem à demanda identificada. Como definiu o ALI-10, seu trabalho consistia em "identificar melhorias e aproximar o empresário das soluções, as soluções que o Sebrae oferece". Olhando em retrospectiva para o início do programa, uma das participantes do programa explica a sua concepção:

A gente é vendedor. Tem esse nome bonito, mas a gente está vendendo os produtos, não impede que você sugira produtos que não são do Sebrae, até mesmo coisas que você possa fazer, por exemplo, desenvolver a visão e missão pro empresário, mas é bom você sugerir alguma coisa do Sebrae, é barato, é custeado. (ALI-6)

Ser capaz de identificar as soluções para oferecê-las aos empresários requereu também aprender sobre os produtos e serviços disponíveis. Nesse sentido, muitos ALI identificaram que, dada essa necessidade, sempre estiveram aquém do que julgavam necessário. Em parte, porque eram muitos produtos e serviços para conhecer e ainda saber como aplicá-los às necessidades identificadas nas empresas. Por outro lado, identificaram a carência de informações sobre essas soluções ao longo do programa. Além de ter informações sobre as soluções disponíveis, sentiram falta de participarem desses eventos para saber que necessidades atendiam. Para eles, conhecer bem as soluções aumentaria a possibilidade de realizar indicações de qualidade. Como concebem seu trabalho como um consultor de vendas, conhecer o produto é uma necessidade essencial. 
Se você pedir pra alguém hoje, qualquer um, pra falar todas as soluções, a gente não sabe... quando eu percebia que a solução não ia fazer diferença, eu direcionava. Por exemplo, o de gestão financeira, ele é muito bom, então eu sempre direcionava, eu falava "isso vai mudar a vida da empresa, você vai perceber que com as informações que você vai ter no curso vai melhorar sua empresa. (ALI-2)

A inserção dos ALI em seu campo de trabalho após a capacitação foi marcada por diversos desafios, e a prospecção de clientes apareceu como uma ameaça. No campo, os ALI foram responsáveis por prospectar e fazer a adesão de 50 empresas de determinado segmento ou região para participar do programa. Esse período foi descrito como extremamente traumático. Além da pressão da meta a ser atingida e da falta de experiência comercial, algumas reações dos empresários geraram experiências extremamente ruins.

Na minha primeira visita, ouvi de uma empresária: pode ir embora daqui! Eu não quero falar com você! Foi super grossa. Acabou com o meu dia. Eu já estava com medo de ir lá, já não tinha domínio do que estava falando, e a mulher me tocou da loja. Cheguei em casa, chorei, chorei, chorei. Eu tinha que aderir oito empresas naquela semana. (ALI-1)

Para realizar a prospecção, os ALI precisaram desenvolver competências comerciais, ligadas às necessidades de conhecer empresas do setor, organizar informações e fazer contato com os empresários para agendar as visitas. Como a maioria dos ALI não possuía experiência na área comercial, precisaram vencer os medos e desenvolver essas características durante o programa. Alguns utilizaram métodos para organizar as visitas aos empresários de maneira atingir as metas semanais.

Eu tinha pavor de prospecção. Ficar ligando sem ter um cadastro de empresas nenhuma. Tem que fazer levantamento de empresa, levantar contato, pesquisar tudo, montar uma planilha dos contatos, fazer visita, depois você sai na rua desesperada atrás de empresa, porque tem o prazo de adesão. (ALI-10)

Eu setorizo as empresas, já na capacitação, eu já agi de forma estratégica, porque eu sabia que não ia trabalhar de carro, então eu tentei aderir empresas próximas umas das outras e o mais próximo de mim, dessa forma, estilo caracol, das empresas mais próximas às empresas mais distantes. (ALI-6)

Na realização do diagnóstico das empresas, a concepção de ALI como consultor de vendas também orientou as ações e o processo de aprendizagem e desenvolvimento de competências dos entrevistados. 0 Radar de Inovação e o Diagnóstico empresarial aparecem nessa fase como os principais instrumentos a serem aprendidos. Além disso, surge a necessidade de desenvolver a capacidade de interpretar os dados levantados por esses instrumentos, pois dessa interpretação decorreria o Plano de Ação, que deveria ser feito junto com os empresários, validado por um consultor sênior e acompanhado pelos ALI.

Depois de realizarem o diagnóstico, havia a necessidade inserir os dados no sistema. Nessa etapa, os ALI tiveram que aprender a utilizar o sistema do Sebrae para efetuarem os registros. Mais do que compreender as funcionalidades do sistema, tiveram que desenvolver uma metodologia própria de registro. Parte significativa do dia de trabalho dos ALI era despendida nas visitas aos empresários e nos deslocamentos. Muitos começaram a levar consigo seus notebooks e tablets para aproveitarem o tempo de espera pelo atendimento do empresário e o deslocamento para fazerem os registros. Como muitos efetuavam os deslocamentos de ônibus, a falta de segurança na cidade os fez mudar de estratégia. Mesmo aqueles que utilizavam moto não sentiam segurança para levar consigo seus equipamentos.

Hoje por exemplo eu estava num dos bairros que visito de manhã, fui lá debaixo de chuva com escolta policial, porque os traficantes estavam lá no bairro hoje. Então, a polícia estava lá correndo 
atrás de traficantes, mas viram que a gente é diferente e foram atrás pra dar um suporte, pra eu poder fazer os atendimentos. (ALI-1)

Muita atenção foi dispensada aos registros e aos planos de ação realizados, pois deveriam passar pelo crivo das consultoras seniores responsáveis pela orientação dos ALI. As ações registradas nos planos eram o principal foco da atenção do trabalho. Pelo menos uma vez por mês os agentes iam até os clientes para verificar se aquelas ações estavam sendo implementadas. Eram necessárias, no mínimo, três ações de inovação implementadas para que os ALI começassem um novo ciclo com os empresários, aplicando, novamente, o Radar de Inovação. Essas metas eram as maiores geradoras de estresse, pois todos tinham seis meses para migrar para o novo ciclo. Esse era o assunto principal das reuniões mensais dos ALI com a coordenação do programa, que buscava estimular, mas também cobrar seu atingimento. Estava em jogo a permanência deles ou não no programa. Conforme resume a ALI-6, "o agente local de inovação é você dar resultado, senão você é desligado".

Eles não conhecem o programa e a primeira sensação que dá neles é "eu não vou conseguir", então meu papel é incentivá-los e dizer que dá, e o papel deles é sempre "pelo amor de Deus aumenta o cronograma" e o meu papel "não dá pra aumentar, dá pra fazer". (Coordenadora do programa)

ALI como consultor de empresas

É exatamente durante o período que antecede o novo ciclo que começou a surgir uma nova concepção de trabalho entre os ALI. A pressão para o atingimento de metas foi um dos gatilhos. Experienciando seu trabalho como um consultor de vendas, esses jovens perceberam que não conseguiriam atingir as metas para migrar para o ciclo seguinte, indicando as soluções disponíveis no Sebrae.

Os responsáveis pelo programa não querem que eu faça, mas eles precisam de ação. Eu tenho que cumprir metas de ações que estão lá no plano de ação. Então, se eu só indicar coisas que o empresário tem que comprar, ele não vai fazer, porque a maioria das pequenas empresas não têm dinheiro nem tempo para fazer cursos. (ALI-3)

A situação os colocou diante de um impasse. Era preciso que as ações indicadas nos planos de ação das 50 empresas que atendiam fossem implementadas. Porém, os empresários não se mostram disponíveis para comprarem, ainda que por valores abaixo do mercado, as soluções do Sebrae. De um lado, a cobrança da coordenação e, de outro, a indisponibilidade do empresário para realizar a ação. Depois de algumas visitas aos empresários e de não verem os planos de ação avançarem, começou a aparecer uma nova concepção de trabalho.

A gente teve que colocar a mão na massa pra evoluir, se não o radar não andaria, se não o empresário não vê o porquê de você estar indo lá, ele não vai querer te receber, ele já tem várias cobranças, ai você chega lá e fala: você fez o que eu te pedi? Não tem muita coerência, então a gente acaba saindo um pouco do que era previsto inicialmente como ALI. (ALI-6)

"Sair um pouco do que era previsto inicialmente" significa ampliar a compreensão do que é ser um ALI. Esse é o movimento que Mann, Dall'Alba e Radcliffe (2007) descrevem como o caminho do desenvolvimento de competências profissionais. 0 momento em que os profissionais migram para uma concepção de trabalho que, além de incluir a concepção anterior, a supera. 
Entre os ALI, a mudança ocorreu a partir do diálogo com as atividades e as demandas delas decorrentes. Esses momentos de construção de novos sentidos sobre a própria atividade podem ser interpretados como práticas reflexivas, à semelhança do proposto por Schön (2000), considerando a intencionalidade, ou engajamento consciente dos ALI, no exame de sua atuação, a fim de melhorarem suas práticas. É possível notar que não se trata apenas do processo de reflexão sobre a ação, quando os indivíduos constroem sentido sobre suas práticas analisando-as em retrospectiva. Os ALI se envolveram em processos de reflexão na ação, ou seja, novos sentidos foram surgindo enquanto realizavam suas atividades. Contudo, reflexão, aqui, não foi uma atividade introspectiva individual, mas se aproximou daquilo que Boud, Cressey e Docherty (2006) denominaram de reflexão pública, pois envolveu práticas interativas na presença de outros. Os ALI construíram juntos a nova concepção em suas conversas presenciais e remotas (grupo de interação formado em uma rede social).

Além da pressão das metas, outro gatilho apareceu: o desejo de realizar um trabalho de qualidade. Aqui, qualidade apareceu em oposição às metas, que foram consideradas quantitativas. Os ALI começaram a construir sentido sobre a relação que estavam estabelecendo com seus clientes. Em vez de aparecer nas empresas para cobrar se essa ou aquela ação prevista nos planos de ação havia sido realizada, começaram a experienciar o desejo de serem reconhecidos como competentes pelos empresários. Isso significava satisfação pelo trabalho realizado e o aumento de sua empregabilidade, considerando que o programa tinha data para terminar.

Aí eu cheguei lá e todo mundo da empresa numa mesa e eu era tipo a consultora do Sebrae. Como é que eu ia dizer "eu sou agente local de inovação, eu sou como se fosse um trainee, eu estou aprendendo também"? Eles têm uma confiança em você, eu vi todas aquelas pessoas, a dona da empresa do meu lado, eu pensei "meu Deus eu não posso ir embora", não posso só falar "fulano, você tem que fazer um curso", eu tenho que contribuir de alguma forma.(ALI-3)

O objetivo maior do programa é identificar melhorias e aproximar o empresário das soluções, as soluções que o Sebrae oferece. Mas fazendo só isso o trabalho fica muito superficial, porque às vezes até por condições econômicas ele não vai ter condições de contratar um serviço, uma consultoria externa então às vezes o empresário não tem como, não tem tempo. (ALI-10)

A necessidade de serem apreciados como profissionais os fez começarem a compreender a si mesmos como consultores das empresas, embora essa concepção de trabalho se afastasse completamente daquilo que foi planejado pelo programa. Exceto uma das agentes, todos os demais migraram para essa concepção de trabalho. Mesmo essa ALI que não experienciava seu trabalho como consultora, ocasionalmente, dependendo da proximidade da relação com alguns clientes, realizava algumas atividades fora do script previsto.

O papel do ALI é assessorar, identificar, mas não tem o papel efetivo do consultor, que é mais profundo e tem mais responsabilidades. Então, assim, eu tentei ao máximo não interferir, seguir a metodologia, mas é claro que no meio do caminho, às vezes até por identificação com algum cliente, você acaba tendo um papel de consultor. Mas eu utilizei mais os serviços do Sebrae, porque confiava neles. (ALI-5)

A concepção dos ALI como consultores de empresas guiou a ação dos agentes para outras direções. Os atributos mobilizados nas competências "saber prospectar empresas", "saber diagnosticar problemas" e "saber intervir na realidade das empresas" ganharam outras dimensões. Isso vai ao encontro dos achados das pesquisas de Sandberg (2000), que afirmou que os atributos assumem diferentes significados quando as concepções de trabalho dos profissionais mudam.

Durante o programa, dada a grave crise da economia, muitas pequenas empresas fecharam, levando à necessidade dos ALI de prospectar novas empresas para se manterem com o número exigido pelo programa. 
Enquanto experienciavam seu trabalho como vendedores, a necessidade de atingir a meta de adesão de 50 empresas os levou a incluírem no programa empresas cujos empresários mostraram baixo comprometimento. Agora, porém, ao buscarem novas adesões, passaram a desenvolver critérios para identificar aqueles que iriam à frente com o programa. Além da entrevista com os empresários, onde tentavam identificar aqueles que mostravam desejo de realizar mudanças em seus negócios, pediam para caminhar pelas dependências das empresas. Aquelas que pareciam "bagunçadas" os levavam a descartar o empresário. Segundo os ALI, se os empresários não eram capazes de organizar minimamente o ambiente de trabalho de sua empresa, provavelmente não se comprometeriam com as sugestões de inovação.

Estabelecer esses critérios para escolher os empresários que iriam aderir ao programa só foi possível por causa do processo reflexivo de quem era participante de uma prática profissional. Para Brandi e Elkjaer (2011), a reflexão, como reconstrução da experiência, é um processo que não é apenas cognitivo, mas envolve sentimentos e atitudes. Provoca mudanças não apenas na compreensão que as pessoas possuem de algo, mas também sobre a maneira de ser no mundo. A aprendizagem, nesses termos, é concebida não apenas como algo que as pessoas sabem, mas também como aquilo em que estão se tornando.

A maneira como os agentes passaram a realizar o diagnóstico também foi transformada por causa da nova concepção de trabalho que começaram a compartilhar. As ferramentas Radar de Inovação e Diagnóstico Empresarial passaram a possuir outro significado. Enquanto na concepção anterior (consultores de vendas) eram os instrumentos centrais para levantar os problemas e oportunidades sobre os quais proporiam ações, agora passaram a ser apenas as ferramentas de legitimação de seu trabalho junto ao Sebrae. Os instrumentos perderam a centralidade em seu trabalho.

A gente tem um diagnóstico muito baseado no trabalho com a indústria, no radar da inovação, mas não são capazes de dar um diagnóstico real da empresa. Isso é um ponto. Então, o meu diagnóstico com empresário é uma coisa, o diagnóstico que eu uso pra medir inovação é outro, são coisas diferentes, porque quando estou lá dentro da empresa eu vejo algumas necessidades, pela conversa que eu tenho, que o radar não vai captar. Então eu preciso resolver ajudar o empresário. Preciso trabalhar com a necessidade da empresa. (ALI-8)

Os instrumentos passaram a ser utilizados para efetuarem o registro no sistema, a fim de atingirem as metas do programa. A nova concepção de trabalho não foi, primariamente, orientada ao programa, mas ao cliente. A necessidade desse cliente que assumiu a primazia no trabalho. Realizar um trabalho de qualidade passou a ter, também, um significado que foi além do desejo de manter a empregabilidade após o programa. Quando os bons resultados começaram a aparecer, os ALI sentiram-se empoderados pelas transformações ocorridas nas empresas após suas recomendações. A ALI-7 afirmou que, ao ouvir de um empresário "você não tem noção do trabalho que você fez aqui", disse, toda orgulhosa, "ouvir isso é sucesso".

A partir dessa concepção voltada às necessidades dos clientes, cresceram as necessidades de aprendizagem, pois os ALI passaram a ter de apoiar ações em áreas que não tinham domínio: planejamento estratégico, finanças, controle de estoque, marcas, registros e patentes, entre outros. 0 processo de aprendizagem passou a ser autodirigido. Todos citaram sites especializados em gestão de negócios como sua fonte principal de consulta. A troca de informações com os outros ALI do programa, cursos online do Sebrae, amigos e familiares com formação em Administração e Economia, grupos de WhatsApp com ALI de outros estados apareceram como fontes de aprendizagem. Nesse sentido, o desenvolvimento de competências dentro da nova concepção de trabalho pode ser caracterizado nos moldes da aprendizagem informal (Lohman, 2003).

A Tabela 1 mostra, de forma resumida, como as competências saber prospectar empresas, saber diagnosticar necessidades e saber intervir assumiram significados diferentes dentro das concepções de trabalho. 
Tabela 1 - Concepções de trabalho dos agentes locais de inovação

\begin{tabular}{l|l|l}
\hline \multirow{2}{*}{ Competências/Recursos } & \multicolumn{2}{|c}{ Concepções } \\
\cline { 2 - 3 } $\begin{array}{l}\text { Saber prospectar empresas: } \\
\text { capacidade de mapear setor, } \\
\text { região, persuasão, argumentação }\end{array}$ & $\begin{array}{l}\text { ALI como consultor de vendas } \\
\text { realizado tendo como foco } \\
\text { central o atingimento das metas. } \\
\text { O quantitativo de empresas é o } \\
\text { critério central. }\end{array}$ & $\begin{array}{l}\text { A como consultor de empresas } \\
\text { a partir do critério da qualidade dos } \\
\text { clientes. O foco central é o diagnóstico } \\
\text { da capacidade de resposta dos clientes } \\
\text { em relação à inovação. }\end{array}$ \\
\hline $\begin{array}{l}\text { Saber diagnosticar necessidades } \\
\text { dos empresários: conhecimento } \\
\text { das ferramentas Radar e Diag- } \\
\text { nóstico, organização }\end{array}$ & $\begin{array}{l}\text { A identificação dos problemas } \\
\text { é baseada na interpretação dos } \\
\text { dados levantados a partir do } \\
\text { Radar e do Diagnóstico. }\end{array}$ & $\begin{array}{l}\text { As ferramentas de Radar e Diagnóstico } \\
\text { são usadas como ponto de partida. } \\
\text { A conversa com os empresários e a } \\
\text { observação aparecem como modos } \\
\text { alternativos de diagnóstico. }\end{array}$ \\
\hline $\begin{array}{l}\text { Saber intervir: plano de ação, } \\
\text { conhecimentos das soluções } \\
\text { Sebrae, criatividade }\end{array}$ & $\begin{array}{l}\text { A intervenção se fundamenta nas } \\
\text { soluções Sebrae e em algumas } \\
\text { ferramentas de gestão. }\end{array}$ & $\begin{array}{l}\text { A intervenção é baseada nas ferramen- } \\
\text { tas aprendidas em sites especializados, } \\
\text { outros agentes locais de inovação e } \\
\text { especialistas. As soluções Sebrae são } \\
\text { pouco utilizadas }\end{array}$ \\
\hline
\end{tabular}

Fonte: Elaborada pelo autor.

\section{Discussão dos resultados}

Essa pesquisa utilizou o método fenomenográfico, cujo objetivo central é mapear as concepções, ou diferentes formas, que um fenômeno é experienciado por um grupo de indivíduos (Marton, 2000). Esse objetivo é atingido quando o pesquisador assume o pressuposto da ontologia relacional, mantendo como foco de atenção a relação entre os sujeitos e tal fenômeno (Bowden, 2005). Ao assumir esse pressuposto, acredita-se que o espaço de resultados, quadro analítico em que são apresentadas as concepções do fenômeno, é capaz de mostrar, também, a relação hierárquica e inclusiva entre essas concepções. Hierárquica, porque estabelece as concepções que são simples (ou parciais) e as que são mais profundas (ou plenas); inclusiva, porque as concepções mais profundas incorporam as mais simples (Marton, 1981).

Esse estudo mostrou que os agentes locais de inovação (ALI) experienciam seu trabalho de duas maneiras. Na primeira (ALI como consultor de vendas), as competências "saber prospectar clientes", "saber diagnosticar necessidades" e "saber intervir" são manifestadas tendo como foco as metas de adesão de clientes, a utilização de ferramentas específicas de diagnóstico e a capacidade de indicar soluções capazes de resolver os problemas identificados. Essa maneira de conceber o trabalho se aproxima daquilo que é definido pelo programa. Por ser uma atividade em que não possuem experiência, os ALI passam a construir sentido sobre o trabalho a partir daquilo que é estabelecido e transmitido pelo Sebrae na capacitação realizada no início do programa. A capacitação é fundamentada no modelo de aprendizagem experiencial (KOLB, 1984). Espera-se que, diante das situações práticas, os ALI sejam capazes de aplicar os conceitos, metodologias e ferramentas ensinadas na capacitação. Assim, é forjada a concepção do "ALI como consultor de vendas", ou seja, alguém que seja capaz de diagnosticar as necessidades da empresa, no que diz respeito à inovação, e indicar a solução disponível no mercado, preferencialmente, do Sebrae.

A segunda forma de experienciar o trabalho (ALI como consultor de empresas) é desenvolvida durante o programa. Experienciar dessa forma o trabalho é agir de maneira não autorizada pelo Sebrae. Durante a capacitação, e ao longo do programa, os ALI ouviam, da coordenadora e dos consultores seniores que os orientavam, que não eram consultores. Deveriam realizar o diagnóstico e indicar a solução disponível do Sebrae e, finalmente, acompanhar sua implantação. Havia uma razão jurídica e uma prática para que isso fosse repetido. Os ALI são bolsistas do CNPq e não fazem parte do quadro de consultores do Sebrae. Portanto, 
agir como tal poderia gerar passivos trabalhistas futuros. Além disso, qualquer recomendação errada por "consultores" inexperientes colocaria o nome da instituição em jogo.

A despeito da orientação, os ALI passam a experienciar o trabalho como consultores. Em vez de indicar as soluções disponíveis, passaram a buscar conhecimento de maneira independente e tentar aplicá-lo nas empresas. Essa forma de experienciar o trabalho vai ao encontro dos achados da pesquisa realizada por Orr (1990) com técnicos de reparos de fotocopiadoras da Xerox. Para essa empresa, a ação competente de seus técnicos se daria a partir da aplicação dos conhecimentos disponíveis em seus manuais técnicos. Os treinamentos desses técnicos se baseavam na transmissão desse conhecimento canônico. Diante das situações práticas, esses conhecimentos prescritos mostravam-se insuficientes e os técnicos passaram a desenvolver práticas não-canônicas para preencher a lacuna entre o conhecimento canônico disponível e a necessidade de agir e de ser reconhecido como um técnico competente.

Essas duas concepções formam o espaço de resultados do fenômeno estudado, ou seja, as maneiras como o trabalho dos ALI pode ser experienciado. Um dos pressupostos centrais da fenomenografia é que qualquer fenômeno pode ser experienciado em um número finito de concepções (Marton, 1994). No espaço de resultados do trabalho dos ALI, a concepção 2 (ALI como consultor de empresas) é mais complexa e absorve a concepção 1 (ALI como consultor de vendas). A Figura 2 mostra a representação gráfica do espaço de resultados.

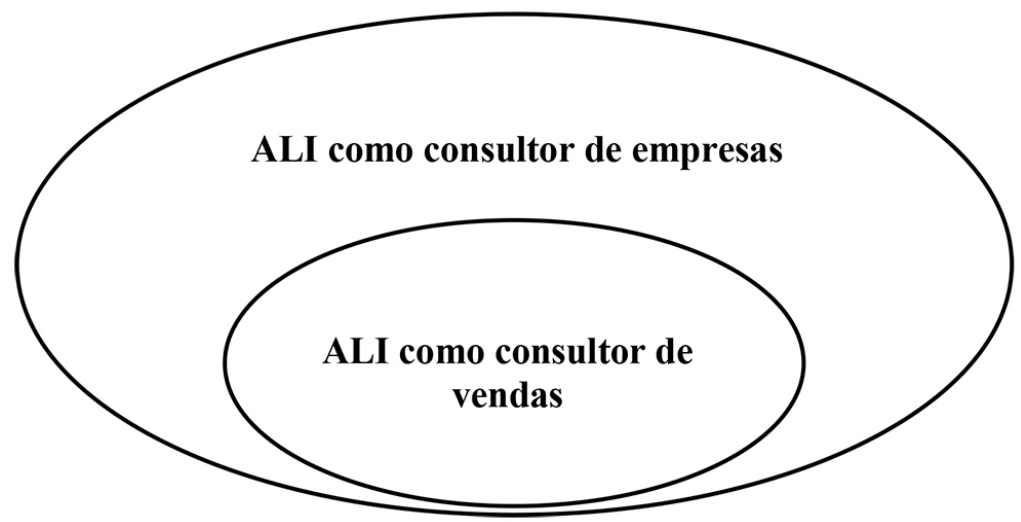

Figura 2 - Espaço de resultados das concepções de gestão Fonte: Elaborada pelo autor.

Até esse ponto, essa pesquisa não se diferenciaria dos demais estudos fenomenográficos, cujo objetivo é mapear as concepções do fenômeno estudado e organizá-las no espaço de resultados, designando a relação entre elas. Contudo, à semelhança da pesquisa realizada por Cherman e Rocha-Pinto (2016), esse trabalho chegou a um achado fortuito. A pesquisa realizada por essas autoras revelou resultados que ajudaram a preencher determinadas lacunas em pesquisas fenomenográficas. Um deles é que os indivíduos podem navegar, de forma dinâmica, entre as concepções de maneira bidirecional (da mais superficial à mais complexa e vice-versa), dependendo do contexto vivenciado. As pesquisas fenomenográficas anteriores sugeriam que o desenvolvimento profissional se tratava de navegar da percepção de trabalho mais simples para a mais complexa.

Porém, na pesquisa realizada por Cherman e Rocha-Pinto (2016) e nos demais estudos fenomenográficos, os gatilhos que causam a mudança de concepção não foram identificados. Esses estudos não ajudam a responder à questão: 0 que faz com que um indivíduo navegue de uma concepção para outra?

Essa pesquisa revelou dois gatilhos: a pressão exercida pelas metas e o desejo de realizar um trabalho de qualidade. Esses dois vetores levaram os ALI a migrarem da concepção 1 para a concepção 2. Essa mudança 
de concepção levou ao desenvolvimento de novos conhecimentos e habilidades, ressignificando as competências "saber prospectar empresas", "saber diagnosticar necessidades" e "saber intervir". Por possuírem foco de atenção diferentes em cada concepção, essas competências passam a assumir novas formas. Isso vai ao encontro dos achados de Sandberg (2000), que já haviam apontado nessa direção. Além disso, essa mudança de concepção mostrou, empiricamente, aquilo que o modelo teórico de desenvolvimento profissional proposto por Mann, Dall'Alba e Radcliffe (2007), mostrado na Figura 1, havia apontado. Esses autores propuseram duas formas de desenvolvimento: a aprendizagem que ocorre sem que o indivíduo mude a sua concepção de trabalho e aquela em que esta é transformada.

A pesquisa com os ALI revelou que houve desenvolvimento profissional que se fundamentou na mudança de concepção. Como mostrado na apresentação dos resultados, essa mudança foi disparada pelos gatilhos da "pressão das metas" e do "desejo de realizar um trabalho de qualidade", que levaram aos ALI a construir um novo sentido para aquilo que faziam.

\section{Conclusão}

Este estudo objetivou analisar o processo de mudança de concepções de trabalho de um grupo de Agentes Locais de Inovação do Sebrae/ES e sua influência no desenvolvimento de competências desses agentes. As análises apontaram para duas concepções de trabalho entre os agentes: Concepção 1 - ALI como consultor de vendas e Concepção 2 - ALI como consultor de empresas.

Alguns estudos fenomenográficos indicam a mudança de concepções como forma essencial para desenvolver a competência dos profissionais (Dall'Alba, 2004; Dall'Alba \& Sandberg, 2006; Dall'Alba, 2009; Sandberg \& Pinnington, 2009; Mann, Dall'Alba \& Radcliffe, 2007). Contudo, não foram encontrados estudos empíricos que identificassem gatilhos para as mudanças nas concepções de trabalho. Esse estudo documentou a "pressão das metas" e o "desejo de realizar um trabalho de qualidade" como gatilhos que promoveram a mudança de concepção de trabalho dos ALI e conduziram ao desenvolvimento de novas competências.

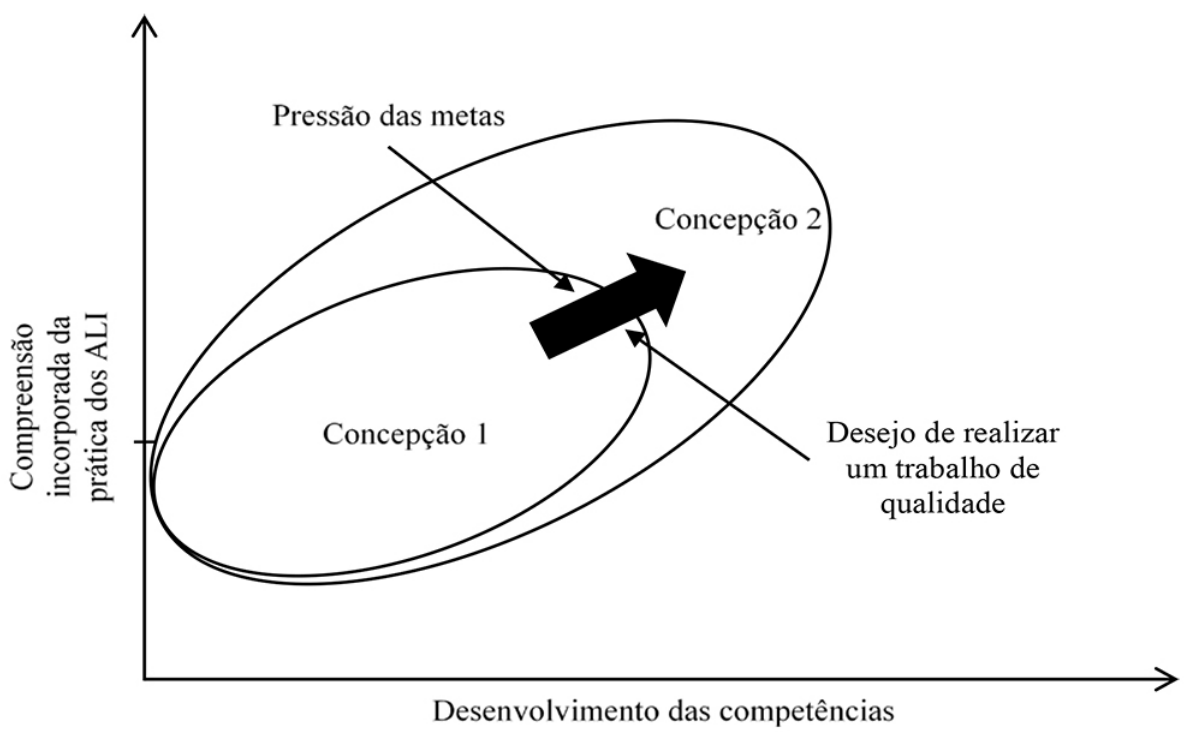

Figura 3 - Proposta de modelo de desenvolvimento de competências e seus gatilhos Fonte: Elaborado pelo autor a partir do modelo de Mann, Dall'Alba e Radcliffe (2007). 
Na Figura 3 é apresentada uma proposta de modelo que mostra o desenvolvimento de competências elaborada a partir dos achados da pesquisa. A mudança da concepção de trabalho mais superficial para a mais profunda ocorreu como resultado das reflexões, individuais e públicas, dos agentes sobre as pressões das metas e a vontade de realizarem um trabalho marcante nas empresas que atendiam. Esse modelo identifica dois gatilhos que impulsionaram a mudança das concepções de trabalho dos profissionais e mostra, empiricamente, aquilo que Mann, Dall'Alba e Radcliffe (2007) haviam proposto teoricamente: novas concepções levam ao desenvolvimento de novas competências.

Feldon e Tofel-Grehl (2018) ressaltam o caráter ideográfico das concepções nos estudos fenomenográficos. Por isso, o espaço de resultados apresenta graficamente as concepções e estabelece a relação entre elas. Esses autores lembram, também, do aspecto nomotético desses estudos. Isso significa dizer que a fenomenografia examina até que ponto as concepções identificadas e as relações entre elas podem ser generalizadas para uma amostra maior, considerando que qualquer fenômeno é experienciado em um número finito de formas. Sob esse aspecto, é necessário ser parcimonioso em relação ao espaço de resultados tratado neste estudo. Como o programa ALI é realizado em diversos estados, são necessários outros estudos desse mesmo fenômeno para corroborar as duas concepções encontradas e os gatilhos que dispararam a mudança entre elas. Essa forma de agir é coerente com a tradição fenomenográfica. É o que tem ocorrido com as concepções de ensino de professores (Trigwell \& Prosser, 1996) cujo espaço de resultados vem sendo revisto e confirmado por estudos realizados em diversas instituições.

Embora tenha sido realizado em uma organização específica, essa pesquisa traz alguns insights para outras organizações. Os achados desse estudo destacam que focalizar o desenvolvimento das competências baseado na mudança das concepções, mais do que em programas de capacitações voltadas para a aprendizagem de determinados conhecimentos e habilidades, mostra-se uma alternativa interessante, pois a nova concepção estimula os profissionais ao autodesenvolvimento, assumindo estes, assim, o protagonismo no processo de aprendizagem. A prática de diálogos reflexivos (Sandberg \& Dall'Alba, 2006) pode ser realizada por gestores e outros profissionais para identificar outros gatilhos que estimulem a mudança para concepções mais profundas de trabalho.

\section{Referências}

Åkerlind, G. S. (2005). Learning about phenomenography: interviewing, data analysis and the qualitative research paradigm. In Bowden, J. A. \& Green, P. Doing developmental phenomenography. Melbourne: RMIT University Press.

Amaro, R. A. \& Brunstein, J. (2013). Implicações das concepções de empreender para o desenvolvimento da competência empreendedora. Revista de Administração Faces Journal, 12(4), 9-29.

Amaro, R. A. \& Brunstein, J. (2014). As contribuições da fenomenografia para os estudos da competência profissional. Revista Alcance, 21 (4).

Barbosa, A. C. Q \& Rodrigues, M. A. (2006). Alternativas metodológicas para a identificação de competências. Boletim Técnico do SENAC, 32(2).

Bittencourt, C., Azevedo, D. \& Froehlich, C. (2013). Na trilha das competências: caminhos possíveis no cenário das organizações. Porto Alegre: Bookman.

Boud, D., Cressey, P. \& Docherty, P. (2006). Productive reflection at work: learning for changing organisations. London: Routledge.

Bowden, J. (2000). The nature of phenomenographic research. In Bowden, J. A. \& Walsh, E. Phenomenography. Melbourne: RMIT University Press. 
Bowden, J. (2005). Records of interactive processes in reaching version 8 of the "success" categories of description. In Bowden, J. A. \& Green, P. Doing developmental phenomenography. Melbourne: RMIT University Press.

Brandi, U. \& Elkjaer, B. (2011). Organizational learning viewed from a social learning perspective. In Easterby-Smith, M. \& Lyles, M. A. (Eds.). Handbook of Organizational Learning \& Knowledge Management. (2a ed.). West Sussex: Wiley.

Brunstein, J., Heidrich, S. \& Amaro, R. A. (2016). Competencies for a fair play in organizations: a phenomenographic analysis of managers' conceptions. Brazilian Business Review, 13(2), 105-134.

Chen, P., Partington, D. \& Wang, J. N. (2008). Conceptual determinants of construction project management competence: a Chinese perspective. International Journal of Project Management, 26(6), 655-664.

Cherman, A. \& Rocha-Pinto, S. R. (2016). Fenomenografia e valoração do conhecimento nas organizações: diálogo entre método e fenômeno. Revista de Administração Contemporânea, 20(5), 630-650.

Colbari, A. (2014) Cultura da inovação e racionalidade econômica no universo do pequeno empreendimento. Interações, 15(2), 237-247.

Dall'Alba, G. (2004). Understanding professional practice: investigations before and after an educational programme. Studies in Higher Education, 29(6), 679-692.

Dall'Alba, G. (2009). Learning professional ways of being: ambiguities of becoming. Educational Philosophy and Theory, 41(1), 34-45.

Dall'Alba, G. \& Sandberg, J. (2006). Unveiling professional development: a critical review of stages models. Review of Educational Research, 76(3), 383-412.

Dutra, J. S. (2008). Competências: conceitos e instrumentos para a gestão de pessoas na empresa moderna. São Paulo: Atlas.

Fazey, J. A. \& Marton, F. (2002). Understanding the space of experiential variation. Active Learning in Higher Education, 3(3), 234-250.

Feldon, D. F. \& Tofel-Grehl, C. (2018). Phenomenography as a foundation for mixed models research. American Behavioral Scientist, 62(7), 887-899.

Fleury, A. \& Fleury, M. T. L. (2001, Edição Especial). Construindo o conceito de competência. Revista de Administração Contemporânea, 183-196.

Goff, L. (2017). University administrators' conceptions of quality and approaches to quality assurance. HigherEducation, 74(1), 179-195.

Jardim, L. S. S. \& Rocha-Pinto, S. R. (2017). Desvelando a competência em rotinas de programação da produção a partir do método fenomenográfico. RevistaAlcance, 24(4), 602-618.

Kettunen, J., Sampson, J. P. \& Vuorinen, R. (2015). Career practitioners' conceptions of social media in career services. British Journal of Guidance \& Counselling, 43(1), 43-56.

Kolb, D. (1984). Experiential learning. Englewood Cliffs, New Jersey: Prentice Hall.

Lamb, P., Sandberg, J. \& Liesch, P. W. (2018). Small firm internationalization unveiled through phenomenography. In: Reuber, A. (Ed.). International Entrepreneurship. JIBS Special Collections. Palgrave Macmillan.

LeBoterf, G. (2003). Desenvolvendo a competência dos profissionais. (3a. ed.). Porto Alegre: Artmed.

Le Deist, F. D. \& Winterton, J. (2005). What is competence? Human Resource Development International, $8(1), 27-46$. 
Lohman, M. C. (2003). Work situations triggering participation in informal learning in theworkplace: a case study of public-school teachers. Performance Improvement Quarterly, 16(1), 40-54.

Mann, L., Dall'Alba, G. \& Radcliffe, G. (2007). Using phenomenography to investigate different ways of experiencing sustainable design. Anais do American Society for Engineering Education Annual Conference, Hawaii: ASEE.

Marton, F. (1981). Phenomenography: describing conceptions of the world around us. Instructional Science, 10, 177-200.

Marton, F. (1994). Phenomenography. In Torsten, H. \& Neville, P. The International Encyclopedia of Education. (2a ed., v. 8). Pergamon.

Marton, F. (2000). The structure of awareness. In Bowden, J. A. \& Walsh, E. Phenomenography. Melbourne: RMIT University Press.

Marton, F. \& Säljö, R. (1976). On qualitative differences in learning 1: outcome and process, British Journal of Educational Psychology, 26, 115-127.

Marton, F. \& Trigwell, K. (2000).Variatioest mater studiorum. Higher Education Research and Development, 19(3), 381-395.

McClelland, D. C. (1973). Testing for Competence rather than intelligence. American Psychologist, 28(1), 1-14.

McKenna, S. (1999). Storytelling and "real" management competence. Journal of Workplace Learning, 11(3), 95-104.

Neto, A. T. S. \& Teixeira, R. M. (2014). Inovação de Micro e Pequenas Empresas: Mensuração do Grau de Inovação de Empresas Participantes do Projeto Agentes Locais de Inovação. Brazilian Business Review, 11(4), 1-29.

Organização para Cooperação Econômica e Desenvolvimento. (2005). Manual de Os/o: proposta de diretrizes para coleta e interpretação de dados sobre inovação tecnológica. Brasília, DF: Finep.

O'Leary, J. \& Sandberg, J. (2017). Managers' practice of managing diversity revealed: a practice-theoretical account. Journal of Organizational Behavior, 38, 512-536.

Orr, J. (1990). Talking about machines: an ethnography of a modern job. PhD Thesis, Cornell University, Ithaca, NY, USA.

Partington, D., Pellegrinelli, S. \& Young, M. (2005). Attributes and levels of programme management competence. International Journal of Project Management, 23, 87-95.

Sandberg, J. (2000). Understanding human competence at work: an interpretative approach. Academy of Management Journal, 43(1), 9-25.

Sandberg, J. \& Dall'Alba, G. (2006). Reframing competence development at work. In Castleton, G., Gerber, R. \& Pillay, H. (Org.), Improving Workplace Learning. New York.

Sandberg, J. \& Targama, A. (2007). Managing understand in organizations. London: Sage Publications.

Sandberg, J. \& Pinnington, A. H. (2009). Professional competence as ways of being: an existential ontological perspective. Journal of Management Studies, 46(7), 1138-1170.

Santos, L. S., Alperstedt, G. D., Leal, F. G. \& Feuerschutte, S. G. (2018). 0 método fenomenográfico na pesquisa científica em administração no Brasil: análise e discussão sobre seu uso. Revista de Ciências da Administração, 20(50), 129-146. 
Schön, D. A. (2000). Educando o profissional reflexivo: um novo design para o ensino e a aprendizagem. Porto Alegre: Artmed.

Sjöström, B. \& Dahlgren, L. O. (2002). Applying phenomenography in nursing research. Journal of Advanced Nursing, 40(3), 339-345.

Strati, A. (2007). Organização e estética. Rio de Janeiro: Editora FGV.

Trigwell, K. \& Prosser, M. (1996). Changing approaches to teaching: a relational perspective. Studies in Higher Education, 21(3), 275-284.

Zarifian, P. (2001). Objetivo competência: por uma nova lógica. São Paulo: Atlas.

\section{Agradecimentos}

Agradeço à FAP - Fundo de Amparo à Pesquisa da Universidade Federal do Espírito Santo e ao Sebrae/ ES - Serviço Brasileiro de Apoio às Micro e Pequenas Empresas pelo apoio dado à pesquisa.

\section{Sobre o Autor}

\section{Rubens de Araújo Amaro}

Professor do Programa de Pós-graduação em Administração da Universidade Federal do Espírito Santo (PPGAdm). Doutor em Administração pela Universidade Presbiteriana Mackenzie. E-mail: rubens.amaro@ufes.br. ORCID: 0000-00034183-3562 